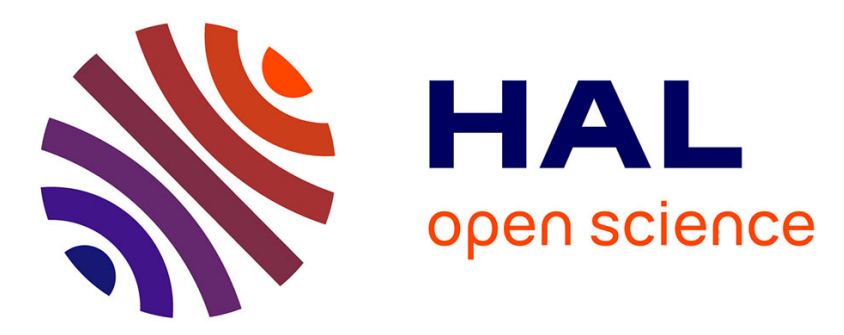

\title{
ON SOME ASPECTS OF SEMICLASSICAL PROPAGATION AND TIME-DEPENDENT DENSITY FUNCTIONAL THEORY
}

H. Kohl, P. Schuck

\section{- To cite this version:}

H. Kohl, P. Schuck. ON SOME ASPECTS OF SEMICLASSICAL PROPAGATION AND TIMEDEPENDENT DENSITY FUNCTIONAL THEORY. International Workshop on Semiclassical and Phase Space Approaches to the Dynamics of the Nucleus, 1987, Aussois, France. pp.C2-317-C2-319, 10.1051/jphyscol:1987248. jpa-00226517

\section{HAL Id: jpa-00226517 https://hal.science/jpa-00226517}

Submitted on 1 Jan 1987

HAL is a multi-disciplinary open access archive for the deposit and dissemination of scientific research documents, whether they are published or not. The documents may come from teaching and research institutions in France or abroad, or from public or private research centers.
L'archive ouverte pluridisciplinaire HAL, est destinée au dépôt et à la diffusion de documents scientifiques de niveau recherche, publiés ou non, émanant des établissements d'enseignement et de recherche français ou étrangers, des laboratoires publics ou privés. 


\title{
ON SOME ASPECTS OF SEMICLASSICAL PROPAGATION AND TIME-DEPENDENT DENSITY FUNCTIONAL THEORY
}

\author{
H. KOHL and P. SCHUCK \\ Institut des Sciences Nucléaires, 53, Avenue des Martyrs. \\ F-38026 Grenoble Cedex, France
}

\begin{abstract}
Résumé - Nous discutons d'une manière simple les relations fondamentales qui existent entre les champs des intégrales de mouvement, la propagation semiclassique et la théorie de la fonctionelle de la densité dépendant du temps.
\end{abstract}

\begin{abstract}
Fundamental connections between the fields of time-dependent integrals of motion, semiclassical propagation and time-dependent density functional theory are discussed in a simple pedestrian's way.
\end{abstract}

In practice we often encounter the following situation. At some arbitrary time $t=0$ a state $\mid a>$ is prepared which is an eigenstate of some operator(s) $\hat{A}: \hat{A}|a>=a| a>$. This prepared state $\mid a>$ is then propagated in a quantum system of interest into $\left|a_{t}\right\rangle=\hat{U}(t)|a\rangle, \hat{U}(t)$ being the time-evolution operator. Since the quantum Liouville space has proved to be a flexible background for semiclassical considerations and since quantum propagation is linear, we may introduce the following concept. Define the operator $\hat{I}_{A}(t):=\hat{U}(t) \hat{A} \hat{U}^{-1}(t)$, then obviously the equation holds : $\hat{I}_{A}(t)\left|a_{t}\right\rangle=a\left|a_{t}\right\rangle$.Operators of that type have a couple of interesting properties. Among the most important ones is the fact, that $\hat{I}_{A}(t)$ is an isospectral deformation of the operator $\hat{A}$. If the latter is bounded from below, $\hat{\mathrm{I}}_{\mathrm{A}}(t)$ can be used to define a minimum principle on sets of time-dependent (TD) states $[1,3,4]$. In the Weyl-Wigner representation the operator $\hat{I}_{A}(t)$ obeys the following equation of motion

$$
\frac{\partial I_{A}}{\partial t}+\frac{2}{\hbar} \sin \left(\frac{\hbar}{2} \Lambda\right) I_{A} \cdot H=0, \quad I_{A}(t=0)=A, \quad \Lambda=\nabla_{p}^{H} \cdot \nabla_{q}^{I}-\nabla_{q}^{H} \cdot \nabla_{p}^{I}
$$

which is the quantum analogue of the classical equation $\partial_{t} I+\{I, H\} P . B$. 0 . The generators of the kinematic symmetries of $H$ are always among the solutions of eq. (1). However, there are (TD) systems with additional and nontrivial closed solutions of eq. (1). (See e.g. [1-5] and for some important results for the classical counterpart of eq. (1) compare [7,8]. An illustration of the application of the Green's function method to equations of type (1) is given in ref. [9]). It should be stressed 
that there are many open and exciting questions, concerning the properties of the solutions of eq. (1). For example the role of the "k-dependent terms" in the Sinoperator has not been really understood so far (compare [9] for an analytical study of a model system). Of course, the question which Hamiltonian systems admit closed solutions of eq. (1) touches a wide and little explored field as well.

There is another class of expansion of the solutions of eq. (1), which should be mentioned in this context [4]. Be $A:=\frac{p^{2}}{2 m}+V(q ; t=0)$ and $H=\frac{p^{2}}{2 m}+V(q, t)$. The ansatz $I=\sum_{\ell=0}^{\infty} \frac{1}{l} I_{\ell}$ leads to a recurrence relation for the functions $I_{\ell}$, which turns out to ${ }^{\ell}=0$ easy to solve in closed form. For the associated operator $I$ one obtains the following expansion

$$
\begin{aligned}
\hat{I}(t)=\frac{\hat{\mathrm{p}}^{2}}{2 \mathrm{~m}}+\hat{\mathrm{V}}(\mathrm{q}, \mathrm{t}=0)+\frac{\left[\frac{\hat{\vec{C}}(\mathrm{q}, \mathrm{t}), \hat{\mathrm{p}}]}{\mathrm{m}}+\frac{\hat{\mathrm{g}}(\mathrm{q}, \mathrm{t})}{\mathrm{m}}+0\left(\frac{1}{\mathrm{~m}^{2}}\right)\right.}{\overrightarrow{\mathrm{C}}(\mathrm{q}, \mathrm{t})=\frac{1}{2}(\nabla \mathrm{v}(\mathrm{q}, \mathrm{t})-\nabla \mathrm{V}(\mathrm{q}, \mathrm{t}=0))} \\
\dot{\mathrm{g}}(\mathrm{q}, \mathrm{t})=2 \overrightarrow{\mathrm{C}}(\mathrm{q}, \mathrm{t}) \cdot \nabla \mathrm{V}(\mathrm{q}, \mathrm{t})
\end{aligned}
$$

where the dot indicates differentiation with respect to time.

The interesting point is that these expansions are universal for each equivalence class of systems considered, in the sense that the potential and its derivatives enter in a functional form. Interacting many body systems may be treated in the same fashion [4] but the detailed convergence properties of this $\mathrm{m}^{-1}$-expansion. are not investigated so far.

In principle density functional theory (DFT) is one of the basic representations of quantum mechanics, since it treats with a quite fundamental question: given the state $\mid \psi(t)>$ of the system at time $t$ and some observable $\hat{\theta}$, be $\rho(q, t)$ the one particle density corresponding to the state $|\psi(t)\rangle$. Is there a map $m_{\theta}$ such that the following diagram of maps commutes ?

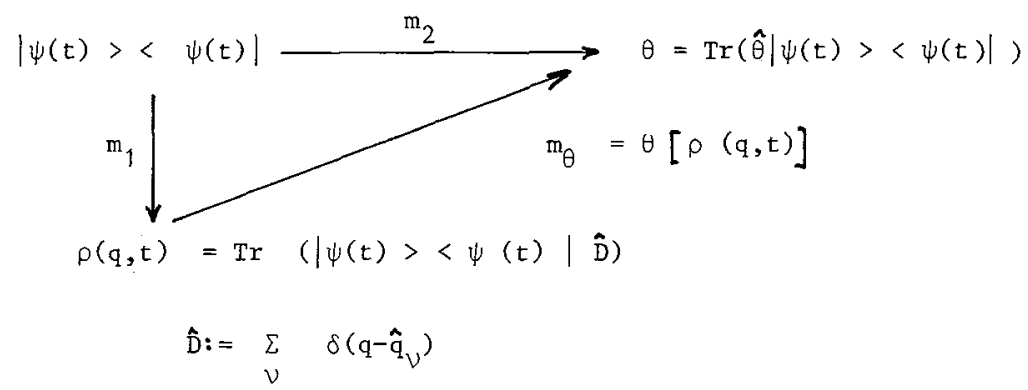

The existence of the map $\mathrm{m}_{\theta}$ would imply that the expectation value $\theta$ of the observable $\hat{\theta}$ may be represented as a functional of the one particle density $\rho(q, t)$. Here the set of admissible observables, states and densities must be specified in detail, which is a highly technical and truly nontrivial problem. (For a discussion of some aspects for time-independent systems, compare the contributions of Levy and Lieb to [10]). 
The question of existence of the map $m_{\hat{*}}$ has been studied recent $1 y[1,2,4]$ using the concepts introduced above. It has been shown as well that the same means may be employed to touch the practical aspects of the problem and determine functionals explicitely, including short time and adiabatic functionals. The possibility to define minimum principles with the help of the operators of type $\hat{I}_{A}(t)$ enters as an essential ingredient in all the steps. Work along these lines continues.

ACKNOWLEDGEMENTS . One of us (H. K) is indebted to R.M. Dreizler (Frankfurt) and MmeM. Durand (Grenoble) for numerous discussions. His stay at the ISN was made possible by a NATO grant.

\section{REFERENCES}

1 H. KoHL, Thesis, University of Frankfurt (1986), unpublished

2 H. KOHL and R.M. DREIZLER, Phys. Lett. 98 A (1983) 95

3 H. KOHL and R.M. DREIZLER, Phys. Rev. Lett. 56 (1986) 1993

4 H. KOHL, unpublished

5 H. KOHL and R.M. DREIZLER, Chem. Phys. Lett. 128 (1986) 189

6 P. RING and P. SCHUCK, The nucler many body problem, Springer (1980)

7 H.R. LEWIS and P.G.L.IEACH, J. Math. Phys. 23 (1982) 2371

8 H.R. LEWIS, J. Math. Phys. 25 (1984) 1139

9 H. KOHL, P. SCHUCK and S. STRINGARI, Nuc1. Phys. A 459 (1986) 265

10 R.M. DREIZLER and J. DA PROVIDENCIA, Density functional methods in physics, Plenum (1985). 